\title{
Epidemias de Mancha de Corinespora em Pepino "Tipo Japonês" sob Cultivo Protegido na Região Norte do Estado do Paraná*
}

\author{
Jaqueline R. Verzignassi, João B. Vida \& Dauri J. Tessmann \\ Departamento de Agronomia, Universidade Estadual de Maringá, CEP 87020-900, Maringá, PR, e-mail: jrverzignassi@uem.br
}

(Aceito para publicação em 23/07/2003)

Autor para correspondência: Jaqueline Rosemeire Verzignassi

\begin{abstract}
Epidemics of corinespora leaf spot in greenhouse cucumber in Northern Paraná State

The leaf spot caused by Corynespora cassiicola on greenhouse

cucumber (Cucumis sativus) has been considered a minor disease in northern Paraná. However, epidemics of this disease have recently been recorded as causing significant losses in this greenhouse crop.
\end{abstract}

Cultivos sucessivos de pepino "tipo japonês" (Cucumis sativus L.) na Região Norte do Estado do Paraná em estufas plásticas, tipo túnel alto, tornaram Corynespora cassiicola (Berk. \& Curt.) Wei, um patógeno de pouca importância para a cultura até recentemente (Kurozawa \& Pavan, Manual de Fitopatologia, v.2, Ceres, 1997), num dos mais importantes nessa modalidade de cultivo. Os primeiros sintomas da doença surgem logo após o transplante, inicialmente sob a forma de pequenas manchas, tipo "flecks", de coloração clara, que evoluem para manchas angulares, com o centro de cor palha e pequeno halo amarelo claro. Nessa fase, os sintomas podem ser confundidos com os da mancha zonada (Leandria momordicae Rangel). Posteriormente, as manchas crescem, tomando formato arredondado, e apresentam centro marrom claro e bordos encharcados de coloração olivácea. O coalescimento das manchas podem provocar seca do limbo foliar (Figura 1). Não tem sido observado sintomas da doença em caule, frutos e raízes; somente nos limbos foliares. A mancha de corinespora tem ocorrido com intensidade nas estufas plásticas nos períodos de primavera e verão, atingindo níveis epidêmicos dentro de poucos dias após a visualização dos primeiros sintomas nas plantas. Estimativas feitas através de comparações entre produtividade de cultivos sadios e de cultivos com epidemias de mancha de corinespora têm mostrado redução na produção em torno de $60 \%$.

Os fungicidas utilizados para o controle de outras manchas foliares em cucurbitáceas não têm apresentado resultados práticos no controle dessa doença. Outras práticas de manejo da cultura como eliminação de restos culturais, maior espaçamento entre plantas e manejo de cortinas laterais das estufas, não têm reduzido a severidade da doença. Os híbridos utilizados na Região têm apresentado alta suscetibilidade à mancha de corinespora. Pesquisas sobre a doença em pepino conduzido sob cultivo protegido são escassas, fazendo-se necessário estudos de epidemiologia, de medidas de controle (químico, varietal, manejo da cultura, entre outros) e de especialização fisiológica do patógeno, visando o melhor entendimento das relações patógeno-hospedeiro e com o objetivo final de definir estratégias de manejo para o controle da doença.
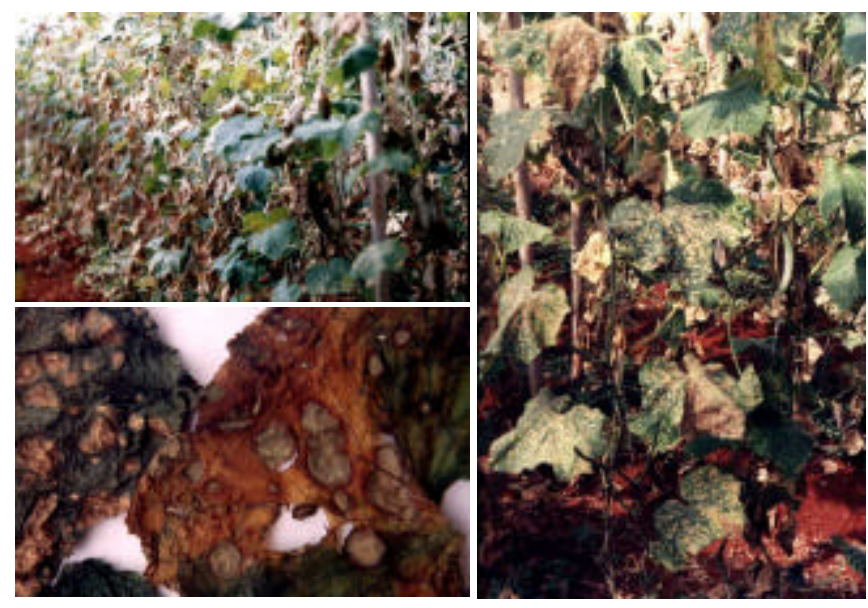

FIG. 1 - Sintomas da mancha de corinespora (Corynespora cassiicola) na cultura de pepino "tipo japonês" (Cucumis sativus) sob cultivo protegido. Maringá, PR, 2003. 